\title{
Private Branding Analysis with the Intervention of Marketing Efforts on Channel Competition
}

\author{
Ding Yuan \\ School of Management, Jinan University, Guangzhou, China \\ Email: 1072589940@qq.com
}

Received 2 February 2016; accepted 23 February 2016; published 26 February 2016

Copyright (C) 2016 by author and Scientific Research Publishing Inc.

This work is licensed under the Creative Commons Attribution International License (CC BY). http://creativecommons.org/licenses/by/4.0/

c) (i) Open Access

\begin{abstract}
Over the past decades, the retail industry has been continuingly prosperous through the constant booming of Chinese economy, a reality that retailers brand their store names or other private labels to products made by unaffiliated manufacturers. However, mass of data shows that retailers are reluctant to maximize their marketing efforts without private labels; from this perspective game theory was used to construct models for three modes, by which two distinguished circumstances depended on whether to adopt private branding. The results reveal a new theoretical insight into private branding choice that retails will not be fully motivated to optimize their marketing efforts on product branded by manufacturers because of the brand specificity. In addition, results also offer an internal condition of private branding strategy and its relevant factors. I've built my hope that this approach of private branding is useful to retailers who need scientific suggestions for crafting an efficient branding strategy.
\end{abstract}

\section{Keywords}

Retail Industry, Brand Specificity, Marketing Efforts

\section{Introduction}

For years, the retailer industry has been continuingly prosperous through the constant booming of Chinese economy. Typically, retailers extend their hands on branding field, to put their store names or other private labels on products made by unaffiliated manufacturers or themselves. Regardless of the original source of these products, sometimes retailers even prefer to use a fresh or unknown label instead of the reputable manufacturer brand or their own store name [1]. Even in the currently hottest industry like e-commerce platform, it still fol- 
lows the essence of retail industry. Dramatic trend prompted by development of private brands constantly influences the brand decision of retailers, manufacturers and consumers.

Quantities of theories have been advanced to research the brand competition between retailers and manufacturers. Salma and Guiomar came up with that when private labels appear, the traditional contradiction of branding right could be coordinated by advertisement compensation contributed by retailers considering the competitiveness between manufacturer and retailer brand [2]. Moreover, literature of Yue and Austin established the advertisement model under the Stackelberg game with dominant retailer supply chain and dominant manufacturer supply chain, which leads to the consideration of some marketing methods like sales promotion and discount which are included in two-stage model. The results reveal that there is a high-positive correlation between payoff and discount of product branded by retailer under circumstance of private branding [3]. While some authors deepen their research with two-tier advertising model, and detailedly research the pricing and advertising strategy of retailers to decide whether to adopt private branding strategy [4]. Some literatures investigated that how private brands survive in a mature product market with high market segmentation, and found that retailers always prefer unknown labels with relatively lower price in initial stage of private branding (Morton and Sayman [5] [6]).

Nonetheless, questions still bother us. Private branding shifts the right of branding from manufacturers to retailers as the transformable power of supply chain status from the first manufacturers to retailers. However, there are still questions about the emergence of private brands while a mass of data shows that retailers are reluctant to maximize marketing efforts without private labels. It seems that acting such an important role makes the retailers be confused about investment of marketing efforts [7] [8]. With the continuous growth of private brand and retail industry, the current researches aren't as competent enough to understand this phenomenon accurately. In a word, there were quite quantities of limitation of Chinese relevant research about this field.

This article aims to provide a comprehensive understanding about the private brand decision-making. To elaborate the traditional conflict between manufacturer and retailer based on brand competition, the reason of retailers' hesitation about marketing efforts is illustrated. This paper is committed to explore an internal condition of private branding strategy and offer more practical management suggestions to reality.

The next content of this paper is structured as follows: a phenomenon of marketing hesitation and corresponding basic model are employed in the next two sections. In Section 4, the Stackelberg model is established and solved with several equilibriums and propositions. Furthermore, the final analysis of solutions and practical suggestions are given in Section 5 eventually.

\section{Brand Specificity}

\subsection{Brand Contradictions}

Over past decades, the private brand keeps booming with retail industry, especially when chain-store operations greatly stimulate the development of retailers [1]. There is no doubt that retailers have enough power to develop a new label or private brand to consumers due to the terminal position advantage. However, the things did not as optimistic as people thought. As yet, a relatively stronger retail could encourage the brand image of a manufacturer-branded product among consumers, but the next effects are exclusive with the brand owner. For example, retailer put extra marketing effort on an unknown brand of manufacturer, obviously it can raise the product's popularity, but eventually the growth of reputation might be stolen by the manufacturer who brands this product, retail get nothing left but the increasing bargaining power of manufacturer.

Actually, similar to the assert specificity, brand also has it's unique specificity, which means retailers don't necessarily need to bear the subsequent effects (positive or negative) after taking any marketing decisions when the product's brand owner is manufacturer [7]. To be more specific, there are three issues in turn triggered by brand specificity.

- The abusive marketing practices adopt by retailers like promotion, depreciation could weak the brand image of a manufacturer-branded product if there isn't a supervised mechanism between retailer and manufacturer.

- As the majority of after-sales service provided by retailer because retailer locate in the terminal position towards consumers. Deterioration of such service quality could harm the Consumer Loyalty of a manufacturer-branded product.

- Retailers won't maximize their marketing investment unless it's fully sure that the subsequent benefits 
wouldn’t be exclusively occupied by manufacturer.

\subsection{Branding Solutions}

As mentioned above, the issues caused by brand specificity turn apart the relationship between retailers and manufacturers and put them towards opposite side. Indeed, retailers waste the excessive marketing resources because the benefits triggered by retailers finally will be specific to the manufacturers who own this product's brand. In fact, these issues could be deal with through several methods. First, a counterbalance mechanism which is used to supervise the inappropriate behaviors adopt by supply chain members absolutely solve this brand contradiction. Second, supply chain integration could also solve the problem of brand specificity by aligning the owner and user of brand into one single corporation. In addition, private branding is an extraordinary solution, essentially it could be considered as a branding integration or a partial integration, signifying to transform the branding right from manufacturer to retailer. Comparing with the previous two solutions, obviously the private branding is the prior strategy considering the applicability of decision, and it's also the reason for the emergence of private brands.

\section{Basic Model}

This chapter attempts to establish a supply chain structure which is composed by a manufacturer and a retailer, a two-stage supply chain where introduce a variable called the Unit Sales influenced by cost of Marketing Efforts as the brand impact index. Considering the current branding status and strength of members in supply chain, a decision that can be adopt strategically by retailers to fulfill the marketing missions relatively maneuverable [9], as the consequence, I only consider the circumstance where retail get the dominant status, then discuss the payoff, pricing and the change of marketing efforts of three modes. Those modes are illustrated as follow:

The first one named with Retailers-Dominant Stackelberg approach (below discussion with RS instead) where retailers only sale the products branded by manufacturer. The next one is Retailers and Manufacturers all incorporate approach which means the whole supply chain adopt the integration strategy to sell and invest together (below discussion with RI instead). The final mode considering the circumstance of private branding by retailers, named with Private Branding in Retailers-Dominant Stackelberg approach (below discussion with PS instead). The specific details of decision variable are elaborated as follow figure (see Figure 1).

\subsection{Parameters and Assumption}

Under Stackelberg Model, I use $P_{1}$ to represent the product branded by manufacturer and $P_{2}$ to represent the product branded by retailer. Assuming that these two products share the same quality and after-sales service, any difference of these substituted goods is coming from the variant branding right.

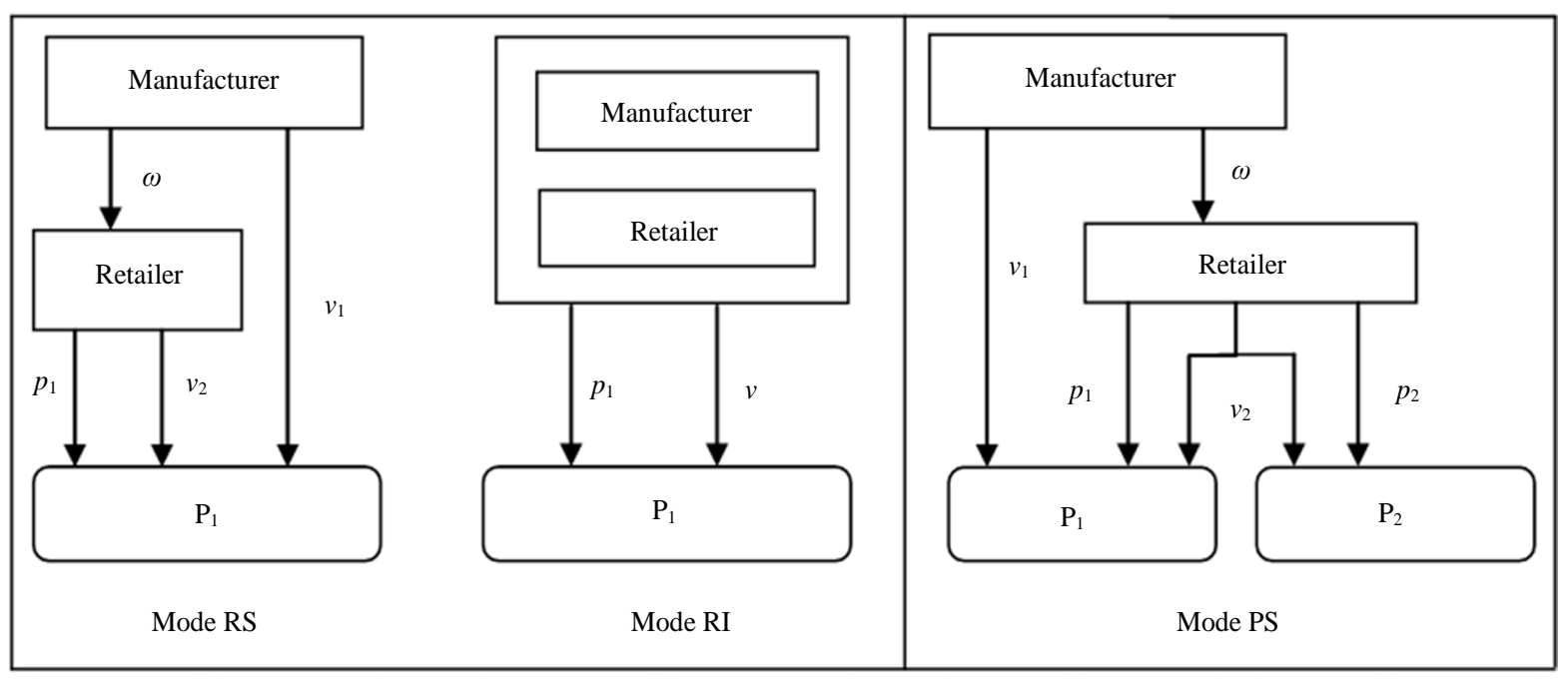

Figure 1. Three modes of two distinguished circumstances depended on whether to private branding. 
So the expectation demand's functions of $P_{1}$ during RS and RI modes are as follow:

$$
Q_{1}=\left(\alpha-\beta p_{1}+\theta_{1} v_{1}+\theta_{2} v_{2}\right)
$$

Then the expectation demand's functions of $P_{1}$ and $P_{2}$ during PS mode are in turn as follow:

$$
\begin{aligned}
& Q_{1}=\left[\alpha-\beta p_{1}+\theta_{1} v_{1}+\theta_{2} v_{2}+\varepsilon\left(p_{2}-p_{1}\right)\right] \\
& Q_{2}=\left[\alpha-\beta p_{2}-\theta_{1} v_{1}+\theta_{3} v_{2}+\varepsilon\left(p_{1}-p_{2}\right)\right]
\end{aligned}
$$

$v_{1}, v_{2}$ on behalf of marketing investment of the manufacturer and retailer, its cost is described as the consuming function of marketing efforts which is subject to the assumption of cost monotone increasing principle. The expectation cost functions are respectively described as: $C_{1}=1 / 2 k v_{1}^{2}$ and $C_{2}=1 / 2 k v_{2}^{2}$.

$\omega$ and $\omega^{\prime}$ respectively represent different wholesale price of $P_{1}$ and $P_{2}, \varepsilon$ represents the cross-price elasticity between $P_{1}$ and $P_{2}$.

$\theta$ represents the Unit Sales influenced by cost of Marketing Efforts as the retailer's and manufacturer's brand impact index, an important dimension of brand impact measuring, could be regarded as manufacturers' and retailers' marketing ability in the product market. Thus $\theta v$ represents the Change of Sales influenced by marketing efforts and brand impact index. Particularly, based on the hypothesis of substitution, the brand impact index of manufacturers is completely exclusive to $P_{1}$ and has additional same level of negative effects on $P_{2}$. However, the brand impact index of retailers thus benefits both two products (assuming $\theta_{2}<\theta_{3}<\theta_{1}<1$ ) [10]. The specific details of $\theta$ among different branding right are elaborated as follow table (see Table 1 ).

\subsection{Basic Functions}

Mode RS: There is only $P_{1}$ in the product market. As the dominant strength of supply chain, retailer determines the marketing investment $v_{2}$ and retail price $p_{1}$ to the consumers where manufacturers determine their marketing investment $v_{1}$ and wholesale price $\omega$, the sequence of decision can be depicted as:

$$
\max _{p_{1}, v_{2}} \pi_{R}^{R S} \rightarrow \max _{\omega, v_{1}} \pi_{M}^{R S}
$$

The expectation payoff's functions of retailers and manufacturers are respectively as follow:

$$
\begin{aligned}
& \pi_{M}^{R S}=\omega\left(\alpha-\beta p_{1}+\theta_{1} v_{1}+\theta_{2} v_{2}\right)-1 / 2 k v_{1}^{2} \\
& \pi_{R}^{R S}=\left(p_{1}-\omega\right)\left(\alpha-\beta p_{1}+\theta_{1} v_{1}+\theta_{2} v_{2}\right)-1 / 2 k v_{2}^{2}
\end{aligned}
$$

Mode RI: During this circumstance, the incorporate supply chain determine $v$ and retail price $p_{1}$ together while manufacturer and retailer equally share the cost of marketing investment, the decision can be depicted as:

$$
\max _{p_{1}, v} \pi_{R, M}^{R I}
$$

The incorporate supply chain payoff's expectation function is:

$$
\pi_{R, M}^{R I}=p_{1}\left(\alpha-\beta p_{1}+1 / 2 \theta_{1} v+1 / 2 \theta_{2} v\right)-1 / 2 k v_{1}^{2}
$$

\begin{tabular}{|c|c|c|}
\hline Change of Sales influenced by Brand Impact of Marketing Efforts & $P_{1}$ & $\boldsymbol{P}_{2}$ \\
\hline Manufacturer (marketing efforts $v_{1}$ ) & $\theta_{1} v_{1}$ & $-\theta_{1} v_{1}$ \\
\hline Retailer (marketing efforts $v_{2}$ ) & $\theta_{2} v_{2}$ & $\theta_{3} v_{2}$ \\
\hline
\end{tabular}

Mode PS: Retailer decides to private branding, there is a mixture of $P_{1}$ and $P_{2}$ towards consumers in market. In such case, manufacturer determines the marketing investment $v_{1}$ as a follower of the supply chain. Then retailer respectively determines marketing investment $v_{2}$ and retail price of $p_{1}$ and $p_{2}$ on the basis of the supplier's reaction. This two-stage decision can be depicted as:

$$
\max _{p_{1}, p_{2}, v_{2}} \pi_{R}^{P S} \rightarrow \max _{\omega, v_{1}} \pi_{M}^{P S}
$$

Table 1. Change of sales triggered by brand impact index and marketing efforts. 
The expectation payoff's functions of retailers and manufacturers are respectively as follow:

$$
\begin{aligned}
\pi_{M}^{P S}= & \omega\left(\alpha-\beta p_{1}+\theta_{1} v_{1}+\theta_{2} v_{2}+\varepsilon p_{2}-p_{1}\right)-1 / 2 k v_{1}^{2} \\
\pi_{R}^{P S}= & \left(p_{1}-\bar{\omega}\right)\left(\alpha-\beta p_{1}+\theta_{1} v_{1}+\theta_{2} v_{2}+\varepsilon p_{2}-p_{1}\right) \\
& +\left(p_{2}-\omega^{\prime}\right)\left(\alpha-\beta p_{2}-\theta_{1} v_{1}+\theta_{3} v_{2}+\varepsilon p_{1}-p_{2}\right)-1 / 2 k v_{2}^{2}
\end{aligned}
$$

\section{Equilibrium Solutions and Propositions}

Considering this two-stage supply chain channel, I use backward induction to solve the Stackelberg Game, implying the dominant strength can determine its variables according to the reaction functions of follower while the information is completely symmetrical in this model. The Equilibrium solutions of three modes can be tabled with four main independent variables (see Table 2).

Proposition 1: Comparing the modes of RS and RI, when $\theta_{1}>\theta_{2}$ or $\theta_{2}>1 / 2(\sqrt{5}+1) \theta_{1}$, the investment of marketing efforts of retailers decrease when there is only one product branded by manufacturer.

Poof: I use the method of backward induction to demonstrate:

If the below inequation was proved,

$$
v_{2_{I S}}-v_{2_{R S}}=\frac{\alpha\left(\theta_{1}+\theta_{2}\right)}{8 k \beta-\left(\theta_{1}+\theta_{2}\right)^{2}}-\frac{\theta_{2} \alpha}{4 k \beta-2 \theta_{1}^{2}-\theta_{2}^{2}}>0
$$

It should follow,

$$
\frac{\theta_{1}^{2}+2 \theta_{1} \theta_{2}+\theta_{2}^{2}}{8 \beta}<k<\frac{-\theta_{1}^{3}-\theta_{1}^{2} \theta_{2}+\theta_{1} \theta_{2}^{2}}{-4 \beta \theta_{1}+4 \beta \theta_{2}}
$$

To testify this variation, I construct the function as follow, $\tau(k)=-4 k \beta \theta_{1}+4 k \beta \theta_{2}+\theta_{1}^{3}+\theta_{1}^{2} \theta_{2}-\theta_{1} \theta_{2}^{2}$, when $\theta_{2}>\frac{\sqrt{5}+1}{2} \theta_{1}$ or $\theta_{1}>\theta_{2}$

$$
\rightarrow \frac{\alpha\left(\theta_{1}+\theta_{2}\right)}{8 k \beta-\left(\theta_{1}+\theta_{2}\right)^{2}}-\frac{\theta_{2} \alpha}{4 k \beta-2 \theta_{1}^{2}-\theta_{2}^{2}}>0
$$

$v_{2}^{R I}>v_{2}^{R S}$ can be testified when the certain condition is satisfied. Particularly this condition is easily satisfied, so I can draw conclusion that in the majority of time, retailers didn't maximize their marketing efforts when there is only manufacturer-branded product.

Proposition 2: When the product branded by retailers emerged, in other word retailers adopt the private branding decision, given $\omega^{\prime}<\bar{\omega}$, retailer will enhance its marketing efforts.

Proof: The proposition is established if the below inequation was proved,

$$
v_{2 P S}-v_{2_{M S}}=\theta_{1}^{2} \theta_{2}\left(\theta_{2}+\theta_{3}\right) \omega^{\prime}+\frac{2 k^{2}\left(\alpha \varepsilon+\alpha(\beta+\varepsilon)-\omega^{\prime} \beta(\beta+2 \varepsilon)\right)}{2 k\left(2 k \beta(\beta+2 \varepsilon)-\varepsilon\left(\theta_{2}+\theta_{3}\right)^{2}-\beta\left(\theta_{2}^{2}+\theta_{3}^{2}\right)\right)}-\frac{\theta_{2} \alpha}{4 k \beta-2-\theta_{2}^{2}}>0
$$

Table 2. Equilibrium solutions of three modes.

\begin{tabular}{cccc}
\hline Mode & \multicolumn{2}{c}{ Equilibrium } & $P_{2}$ \\
\hline RS $\frac{2 \theta_{1} \alpha}{4 k \beta-2 \theta_{1}^{2}-\theta_{2}^{2}}$ & $\frac{\theta_{2} \alpha}{4 k \beta-2 \theta_{1}^{2}-\theta_{2}^{2}}$ & $P_{1}$ & None \\
RI $\frac{\alpha\left(\theta_{1}+\theta_{2}\right)}{8 k \beta-\left(\theta_{1}+\theta_{2}\right)^{2}}$ & $\frac{\alpha\left(\theta_{1}+\theta_{2}\right)}{8 k \beta-\left(\theta_{1}+\theta_{2}\right)^{2}}$ & $\frac{3 k \alpha}{4 k \beta-2 \theta_{1}^{2}-\theta_{2}^{2}}$ & None \\
PS $\frac{2 \theta_{1} \alpha}{4 k \beta-2 \theta_{1}^{2}-\theta_{2}^{2}}$ & $\frac{\theta_{1}^{2} \theta_{3}\left(\theta_{2}+\theta_{3}\right) \bar{\omega}+2 \alpha k^{2}(\varepsilon+(\beta+\varepsilon))}{2 k\left(2 k \beta(\beta+2 \varepsilon)-\varepsilon\left(\theta_{2}+\theta_{3}\right)^{2}-\beta\left(\theta_{2}^{2}+\theta_{3}^{2}\right)\right)}$ & $\frac{\theta_{1}^{2} \theta_{2}\left(\theta_{2}+\theta_{3}\right) \omega^{\prime}+2 k^{2}\left(\alpha \varepsilon+\alpha(\beta+\varepsilon)-\omega^{\prime} \beta(\beta+2 \varepsilon)\right)}{2 k\left(2 k \beta(\beta+2 \varepsilon)-\varepsilon\left(\theta_{2}+\theta_{3}\right)^{2}-\beta\left(\theta_{2}+\theta_{3}^{2}\right)\right)}$ & $\frac{\beta \theta_{1}^{2}\left(\theta_{2}-\theta_{3}\right) \bar{\omega}+k \alpha\left(\beta \theta_{2}+\varepsilon\left(\theta_{2}+\theta_{3}\right)\right)}{2 k^{2} \beta(\beta+2 \varepsilon)-\varepsilon k\left(\theta_{2}+\theta_{3}\right)^{2}-k \beta\left(\theta_{2}^{2}+\theta_{3}^{2}\right)}$ \\
\hline
\end{tabular}


Because the equilibrium solution can't be minus, it must be subject to $8 k \beta>\left(\theta_{1}+\theta_{2}\right)^{2}, 4 k \beta>2 \theta_{1}^{2}+\theta_{2}^{2}$, so $v_{2}^{P S}-v_{2}^{R S}>0$ must follow:

$$
\begin{aligned}
& \frac{k \alpha}{4 k \beta-2 \theta_{1}^{2}-\theta_{2}^{2}}-\frac{2 k \alpha \beta\left(\beta \theta_{2}+2 \varepsilon \theta_{3}\right)}{\left(4 k \beta-2 \theta_{1}^{2}-\theta_{2}^{2}\right)\left(2 k \beta(\beta+2 \varepsilon)-\beta\left(\theta_{2}^{2}+\theta_{3}^{2}\right)\right)} \\
& <\omega^{\prime}<\frac{2 k \alpha}{4 k \beta-\theta_{1}^{2}-\theta_{2}^{2}}+\frac{\alpha \theta_{3}\left(\beta \theta_{3}+\varepsilon\left(\theta_{2}+\theta_{3}\right)\right.}{4 k \beta(\beta+2 \varepsilon)-2 \varepsilon\left(\theta_{2}+\theta_{3}\right)^{2}+\beta\left(\theta_{2}^{2}+\theta_{3}^{2}\right)}
\end{aligned}
$$

According to

$$
\bar{\omega}=\frac{2 k \alpha}{4 k \beta-2 \theta_{1}^{2}-\theta_{2}^{2}}<\frac{2 k \alpha}{4 k \beta-\theta_{1}^{2}-\theta_{2}^{2}}
$$

And

$$
\begin{aligned}
& \frac{\alpha \theta_{3}\left(\beta \theta_{3}+\varepsilon\left(\theta_{2}+\theta_{3}\right)\right)}{4 k \beta(\beta+2 \varepsilon)-2 \varepsilon\left(\theta_{2}+\theta_{3}\right)^{2}+\beta\left(\theta_{2}^{2}+\theta_{3}^{2}\right)}>0 \\
& \rightarrow \bar{\omega}<\frac{2 k \alpha}{4 k \beta-\theta_{1}^{2}-\theta_{2}^{2}}+\frac{\alpha \theta_{3}\left(\beta \theta_{3}+\varepsilon\left(\theta_{2}+\theta_{3}\right)\right)}{4 k \beta(\beta+2 \varepsilon)-2 \varepsilon\left(\theta_{2}+\theta_{3}\right)^{2}+\beta\left(\theta_{2}^{2}+\theta_{3}^{2}\right)}
\end{aligned}
$$

So when it's assumed that $\omega^{\prime}<\bar{\omega}, v_{2}^{P S}-v_{2}^{R S}>0$. Combing the conclusions of Proposition 1 and Proposition 2 , it can be interred that the investment of marketing efforts in mode RS is lowest among three modes.

Proposition 3: Comparing the mode RS and PS, given $\omega^{\prime}<\bar{\omega}$, the payoff of retailer in PS mode will be higher than RS mode, implying that retailers whether to choose private branding strategy will depend on a threshold of the wholesale price $\omega_{0}$. When retailers can make sure that products' source cost is satisfied with super-threshold value, retailers are fully motivated to private branding rather than passively accept the market with single manufacturer-branded products.

Proof: I use backward induction to prove that.

$$
\pi_{R}^{P S}=\frac{2 k \theta_{1}^{2} \bar{\omega}+4 k^{3}(\beta+2 \varepsilon)\left(\alpha-\beta \omega^{\prime}\right)^{2}-k^{2}\left(\theta_{2}-\theta_{3}\right)^{2}\left(\alpha-\beta \omega^{\prime}\right)^{2}}{4 k^{2}\left[2 k \beta(\beta+2 \varepsilon)-\varepsilon\left(\theta_{2}+\theta_{3}\right)^{2}-\beta\left(\theta_{2}^{2}+\theta_{3}^{2}\right)\right]}
$$

Assume $\pi_{R}^{P S} \geq \pi_{R}^{R S}$, it must follow

$$
\omega^{\prime} \leq \frac{+4 \alpha\left(4 k \beta-2 \theta_{1}^{2}-\theta_{2}^{2}\right)\left(4 k \beta(\beta+2 \varepsilon)-k \beta\left(\theta_{2}-\theta_{3}\right)^{2}\right)}{\left(4 k \beta-2 \theta_{1}^{2}-\theta_{2}^{2}\right)\left(4 k^{3} \beta^{2}(\beta+2 \varepsilon)-k^{2} \beta^{2}\left(\theta_{2}-\theta_{3}\right)^{2}-2 k \beta \theta_{1}^{2}\left(2 \theta_{1}^{2}-\theta_{2}^{2}+\theta_{3}^{2}\right)\right)}=\omega_{0}
$$

According to the inequation, $\theta_{3}>\theta_{2}, 4 k \beta>2 \theta_{1}^{2}+\theta_{2}^{2}$, it can be deduced that

$$
\omega_{0}>\frac{k \alpha\left[4(\beta+2 \varepsilon)-\theta_{2}^{2}\right]}{4 k \beta(\beta+2 \varepsilon)}
$$

Because the equilibrium solution can't be minus, $2(\beta+2 \varepsilon)>\left(\theta_{2}^{2}+\theta_{3}^{2}\right)>k \alpha$, it can be deduced that

$$
\begin{aligned}
\frac{k \alpha\left[4(\beta+2 \varepsilon)-\theta_{2}^{2}\right]}{4 k \beta(\beta+2 \varepsilon)}>\frac{2 k \alpha}{4 k \beta-2 \theta_{1}^{2}-\theta_{2}^{2}}=\bar{\omega} \\
\rightarrow \omega_{0}>\bar{\omega}
\end{aligned}
$$

Proposition 4: Threshold of the wholesale price $\omega_{0}$ can be considered as an internal condition of private branding decision, and $\omega_{0}$ is subject to increasing function of $\theta_{1}$ and decreasing function of $\theta_{3}$. 
Proof: According to $\theta_{3}>\theta_{2}$, it can be demonstrated that

$$
\frac{\partial \omega_{0}}{\partial \theta_{1}}>\frac{2 k \alpha \theta_{1}\left(\theta_{3}^{2}-\theta_{2}^{2}\right)}{4 k^{3} \beta^{2}(\beta+2 \varepsilon)-\theta_{1}^{4}\left(\theta_{2}+\theta_{3}\right)^{2}+2 k \beta \theta_{1}^{2}\left(2 \theta_{1}^{2}-\theta_{2}^{2}+\theta_{3}^{2}\right)}>0
$$

According to $\theta_{3}>\theta_{2}$ and $2(\beta+2 \varepsilon)>\left(\theta_{2}^{2}+\theta_{3}^{2}\right)>k \alpha$, it can be demonstrated that

$$
\frac{\partial \omega_{0}}{\partial \theta_{3}}<\frac{k \alpha\left(2 \theta_{1}^{2} \theta_{2}-2 k \beta\left(\theta_{2}-\theta_{3}\right)\right)}{4 k^{3} \beta^{2}(\beta+2 \varepsilon)-k^{2} \beta^{2}\left(\theta_{3}-\theta_{2}\right)^{2}-\theta_{1}^{4}\left(\theta_{2}+\theta_{3}\right)^{2}+2 k \beta \theta_{1}^{2}\left(2 \theta_{1}^{2}-\theta_{2}^{2}+\theta_{3}^{2}\right)}<0
$$

Proposition 5: Comparing the retail price of mode RS RI and PS, the sequence of retailer price among three modes and two different branded products can be depicted as $p_{1}^{R S}>p_{1}^{R I}>p_{1}^{p S}>p_{2}^{P S}$.

Proof: After simplification of difference among those retail prices of respective circumstances, simplest formula can be inferred as follow:

$$
\begin{aligned}
& p_{1}^{R S}-p_{1}^{R I}=\frac{4 k \alpha}{\frac{16}{3} k \beta-\frac{8}{3} \theta_{1}^{2}-\frac{4}{3} \theta_{2}^{2}}-\frac{4 k \alpha}{8 k \beta-\left(\theta_{1}+\theta_{2}\right)^{2}} \\
& p_{1}^{R I}-p_{1}^{P S}>\frac{(2 k \beta+\varepsilon)\left(\theta_{1}^{2}\left(\theta_{2}+\theta_{3}\right)^{2}-2 \theta_{1}^{2} \theta_{2}\left(\theta_{2}+\theta_{3}\right)\right)}{2 k\left(2 k \beta(\beta+2 \varepsilon)-\varepsilon\left(\theta_{2}+\theta_{3}\right)^{2}-\beta\left(\theta_{2}^{2}+\theta_{3}^{2}\right)\right)} \\
& p_{2}^{P S}-p_{1}^{P S}<\frac{\theta_{1}^{2}\left(\theta_{2}-\theta_{3}\right)\left(\theta_{2}+\theta_{3}\right)\left(\omega^{\prime}-\bar{\omega}\right)+2 k^{2}(\alpha \varepsilon+\alpha(\beta+\varepsilon))}{2 k\left(2 k \beta(\beta+2 \varepsilon)-\varepsilon\left(\theta_{2}+\theta_{3}\right)^{2}-\beta\left(\theta_{2}^{2}+\theta_{3}^{2}\right)\right)}
\end{aligned}
$$

According to equilibrium solution can't be minus: $\theta_{2}-\theta_{3}<0,8 k \beta>\left(\theta_{1}+\theta_{2}\right)^{2}$, and $\left(\theta_{2}+\theta_{3}\right)^{2}>2 \theta_{2}\left(\theta_{2}+\theta_{3}\right)$, derivate that

$$
\begin{aligned}
& 8 k \beta-\left(\theta_{1}+\theta_{2}\right)^{2}-\frac{16}{3} k \beta+\frac{8}{3} \theta_{1}^{2}+\frac{4}{3} \theta_{2}^{2}>\frac{1}{3}\left(6 \theta_{1}^{2}+2 \theta_{2}^{2}\right)>0 \\
& \rightarrow p_{1}^{R S}>p_{1}^{R I}>p_{1}^{p S}>p_{2}^{P S}
\end{aligned}
$$

\section{Conclusions and Suggestions}

This paper aims to research the reason why retailers are always reluctant to maximize their marketing efforts and how it changes in different channel structures in order to explore an efficient private branding strategy.

As stated above, game theory was used to construct models with three modes, by which two distinguished circumstances depended on whether to adopt private branding. The results reveal that retails will not be fully motivated to optimize their investment of marketing efforts on product branded by manufacturers because of the brand specificity; nevertheless, this status can be improved by private branding strategy of retailers. In addition to these, the comparison of modes also offers an internal condition of private branding which is a cost threshold of the wholesale price $\omega_{0}$, and it's also highly correlative with the impact index among different branding rights. Moreover, this research found that the private branding choice can benefit for the consumer surplus as the same effectiveness of supply chain integration decision, and retailers prefer low-price strategy when private labels are firstly initiated in product markets.

I need to admit that there are still many limitations in this paper. I will consider the coordination contract between the retailers and manufacturers as a counterbalance factor in future study, and put forward on elaborating the quantitative elements for accurately measuring the cost threshold which is mentioned above. I've built my hope that this approach of private branding is useful to retailers who need scientific suggestions for crafting an efficient branding strategy.

\section{References}

[1] Raju, J.S., Sethuraman, R. and Dhar, S.K. (1995) The Introduction and Performance of Store Brands. Management 
Science, 41, 957-978. http://dx.doi.org/10.1287/mnsc.41.6.957

[2] Salma, K. and Guiomar, M.H. (2009) A Dynamic Model for Advertising and Pricing Competition between National and Store Brands. European Journal of Operational Research, 193, 451-467. http://dx.doi.org/10.1016/j.ejor.2007.11.043

[3] Yue, J.F., Austin, J. and Wang, M.C. (2006) Coordination of Cooperative Advertising in a Two-Level Supply Chain When Manufacturer Offers Discount. European Journal of Operational Research, 168, 65-85. http://dx.doi.org/10.1016/j.ejor.2004.05.005

[4] Szmerekovsky, J.G. and Zhang, J. (2009) Pricing and Two-Tier Advertising with One Manufacturer and One Retailer. European Journal of Operational Research, 197, 785-791. http://dx.doi.org/10.1016/j.ejor.2008.07.014

[5] Morton, S. and Zettlemeyer, F. (2004) The Strategic Positioning of Store Brands in Retail-Manufacture Negotiations. Review of Industrial Organization, 24, 125-139.

[6] Sayman, S., Hoch, S.J. and Raju, J.S. (2002) Positioning of Store Brands. Marketing Science, 21, 378-397. http://dx.doi.org/10.1287/mksc.21.4.378.134

[7] Chen, S.F. (2010) Transaction Cost Implication of Private Branding and Empirical Evidence. Strategic Management Journal, 31, 371-389.

[8] Chen, S.F. (2008) A Transaction Cost Rationale for Private Branding and Its Implications for the Choice of Domestic vs Offshore Outsourcing. Academy of International Business, 40, 156-175. http://dx.doi.org/10.1057/palgrave.jibs.8400419

[9] Fan, X.J. and Chen, H.M. (2011) Research on the Effect of Private Label Introduction on Channel Competition. Chinese Journal of Manage Science, 19, 80-87.

[10] Lu, X. and Huo, J.Z. (2014) Competition Game of National and Store Brands with Advertisement Intervention. Journal of Systems \& Management, 23, 175-178. 